\title{
Relationship between Nanoscale Supramolecular Structure, Effectiveness of Hydrogen Bonds, and Appearance of Debye
}

\section{Process}

\author{
Karolina Jurkiewicz $^{1,2, *}$, Barbara Hachuła ${ }^{2,3}$, Ewa Kamińska ${ }^{4}$, Katarzyna Grzybowska ${ }^{1,2}$ \\ Sebastian Pawlus ${ }^{1,2}$, Roman Wrzalik ${ }^{1,2}$, Kamil Kamiński ${ }^{1,2}$, Marian Paluch ${ }^{1,2}$ \\ ${ }^{1}$ August Chełkowski Institute of Physics, University of Silesia in Katowice, Chorzów, Poland \\ ${ }^{2}$ Silesian Center for Education and Interdisciplinary Research, Chorzów, Poland \\ ${ }^{3}$ Institute of Chemistry, University of Silesia in Katowice, Katowice, Poland \\ ${ }^{4}$ Faculty of Pharmaceutical Sciences, Medical University of Silesia in Katowice, Sosnowiec, Poland \\ * Email: karolina.jurkiewicz@us.edu.pl
}


1. Comparison of FTIR spectra of studied liquids in $\mathrm{CCl}_{4}$ solution (0.1 mole fraction)
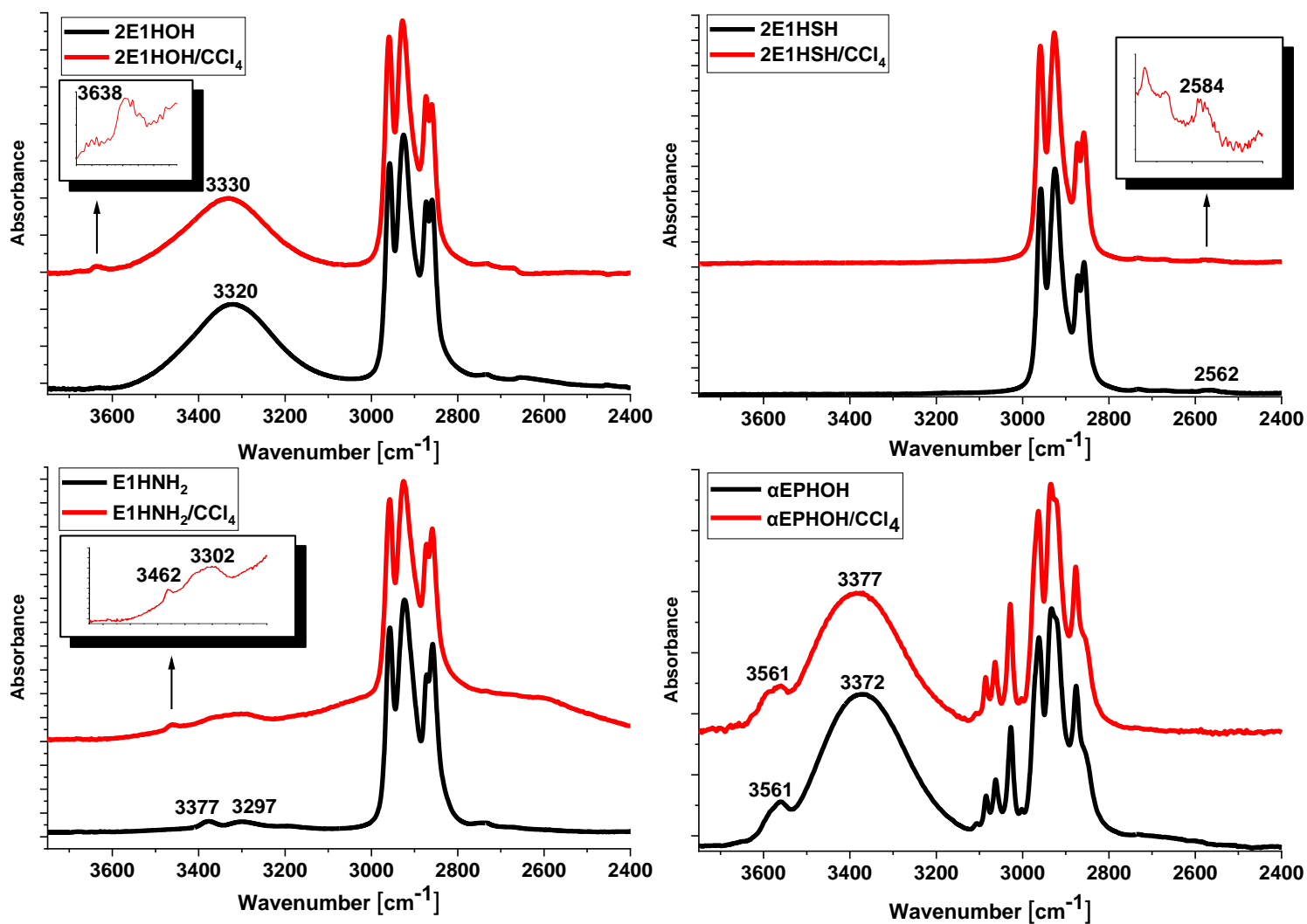

Figure S1. FTIR spectra of $2 \mathrm{E} 1 \mathrm{HOH}, 2 \mathrm{E} 1 \mathrm{HNH}_{2}, 2 \mathrm{E} 1 \mathrm{HSH}$, and $1 \mathrm{PH} 2 \mathrm{BOH}$ in $\mathrm{CCl}_{4}(0.1 \mathrm{~mole}$ fraction) in the $3750-2400 \mathrm{~cm}^{-1}$ frequency range, measured at $293 \mathrm{~K}$.

2. Comparison of FTIR spectra at $293 \mathrm{~K}$ and at $173 \mathrm{~K}$
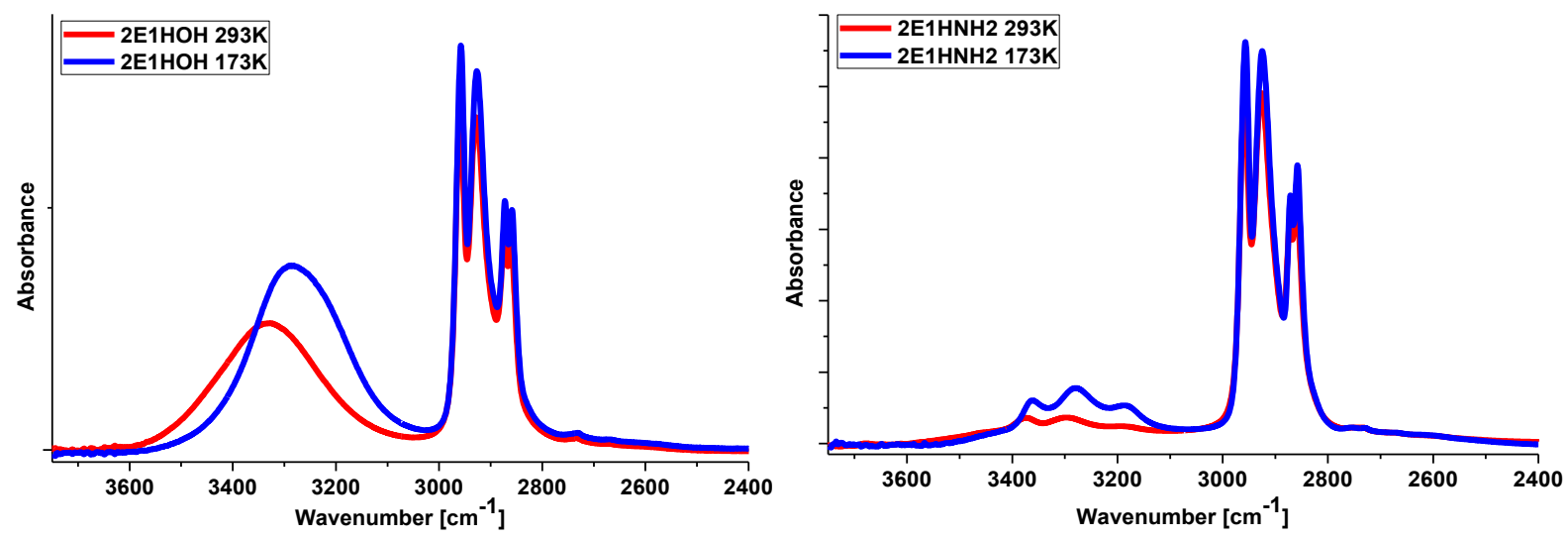

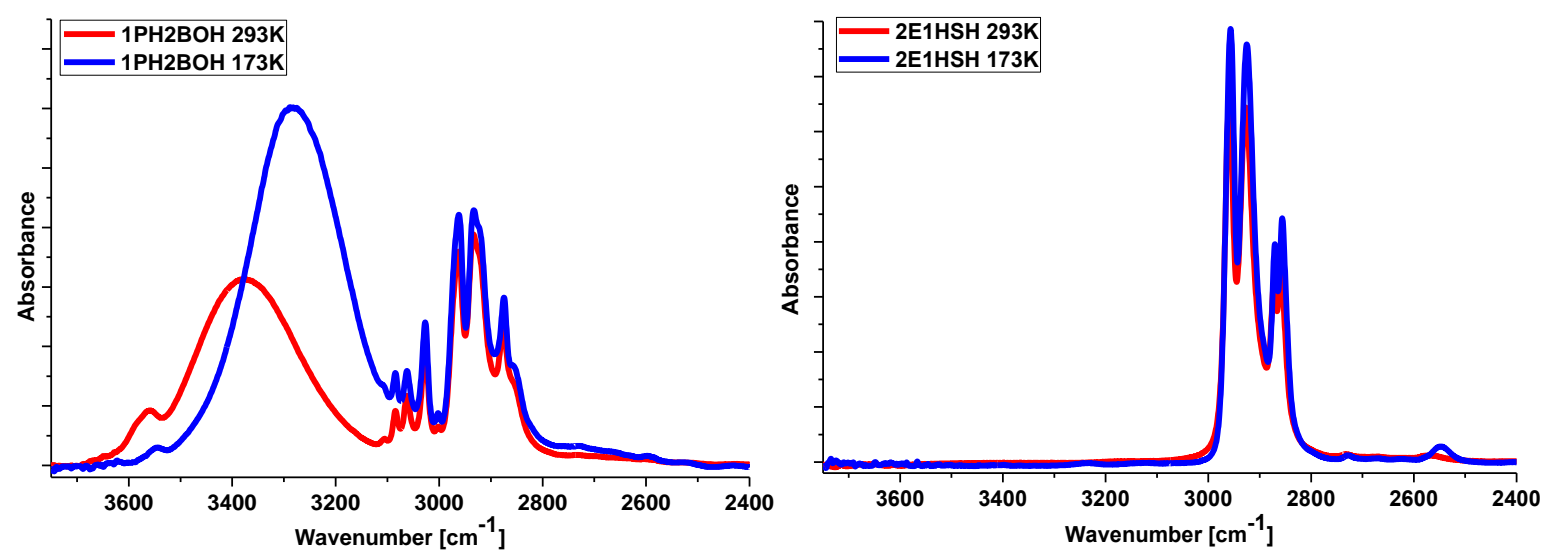

Figure S2. Effect of temperature on the FTIR spectra of $2 \mathrm{E} 1 \mathrm{HOH}, 2 \mathrm{E} 1 \mathrm{HNH}_{2}, 1 \mathrm{PH} 2 \mathrm{BOH}$, and $2 \mathrm{E} 1 \mathrm{HSH}$ in the $3750-2400 \mathrm{~cm}^{-1}$ frequency range ( $293 \mathrm{~K}$ - red line, $173 \mathrm{~K}$ - blue line).
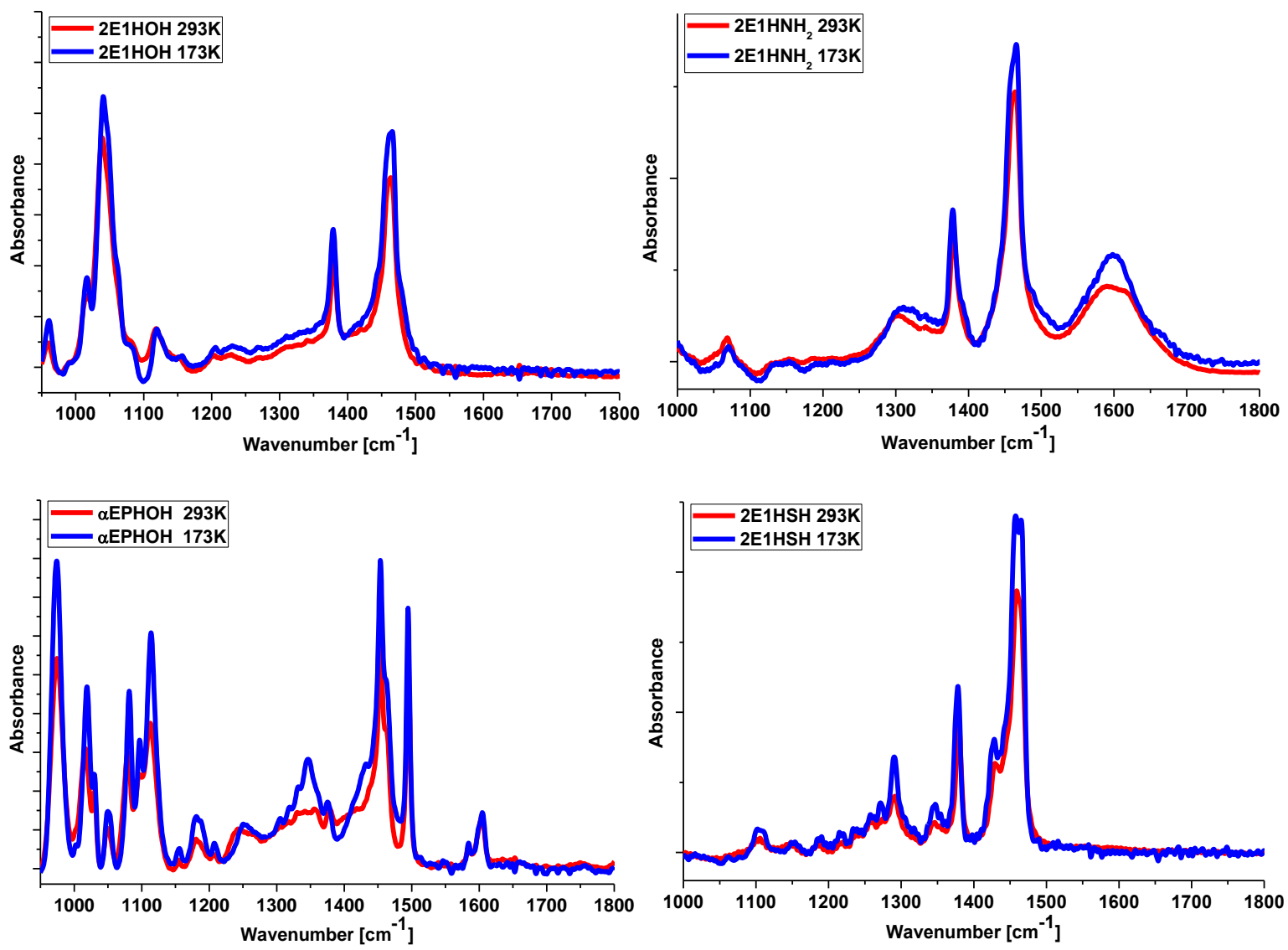

Figure S3. Effect of temperature on the FTIR spectra for 2E1HOH and $1 \mathrm{PH} 2 \mathrm{BOH}$ in the $850-1800$ $\mathrm{cm}^{-1}$ frequency region, and for $2 \mathrm{E} 1 \mathrm{HNH}_{2}$ and $2 \mathrm{E} 1 \mathrm{HSH}$ in the $1000-1800 \mathrm{~cm}^{-1}$ frequency range (293 K - red line, $173 \mathrm{~K}$ - blue line). 


\section{X-ray diffraction data analysis}

The XRD patterns collected for the studied compounds at $293 \mathrm{~K}$ and $173 \mathrm{~K}$ were corrected for background scattering. Then all diffractograms at $293 \mathrm{~K}$ were normalized to 1 at the maximum of the main diffraction peak. The diffractograms at $173 \mathrm{~K}$ were normalized to those obtained at $293 \mathrm{~K}$ for each compound so that the intensity functions match for high scattering vector range from around $40 \AA^{-1}-20 \AA^{-1}$, where only intramolecular correlations contribute to the diffraction data. Then, the diffraction data were fitted in the range $0.25-1.8$ $\AA^{-1}$ with two PseudoVoigt functions (in case of $2 \mathrm{E} 1 \mathrm{HSH}$ only one PseudoVoigt function was used for data at $293 \mathrm{~K}$ ). If the fit converges, it delivers the value of the main peak position $Q_{\mathrm{mp}}$, pre-peak position $Q_{\mathrm{pp}}$, main and pre-peak full width at half maximum, $F W H M_{\mathrm{mp}}$ and $F W H M_{\mathrm{pp}}$, respectively. Furthermore, the integrated intensity of main and pre-peak, $I_{m p}$ and $I_{p p}$, respectively, were determined. Moreover, if we adopt an interpretation of the diffraction peaks in term of "quasicrystalline" model, the main peak and pre-peak correlation distances, $d_{m p}$ and $d_{p p}$, as well as main peak and pre-peak-related correlation lengths, $L_{m p}$ and $L_{p p}$, respectively can be calculated as follows: $d_{m p}=2 \pi / Q_{\mathrm{mp}}, d_{p p}=2 \pi / Q_{\mathrm{pp}}, L_{m p}=2 \pi / F W H M_{\mathrm{mp}}, L_{p p}=$ $2 \pi / F W H M_{\mathrm{pp}}$. An example of a fit to the diffraction data for $2 \mathrm{E} 1 \mathrm{HOH}$ at $293 \mathrm{~K}$ is showed in Figure S3. The structural parameters obtained from the diffraction data analysis were collected in Table S1. Figure S4 presents a sketch of the $2 \mathrm{E} 1 \mathrm{HOH}$ structure at $293 \mathrm{~K}$ with typical distances contributing to the main diffraction peak and pre-peak indicated by arrows (the figure was composed based on the structure proposed in reference ${ }^{1}$.

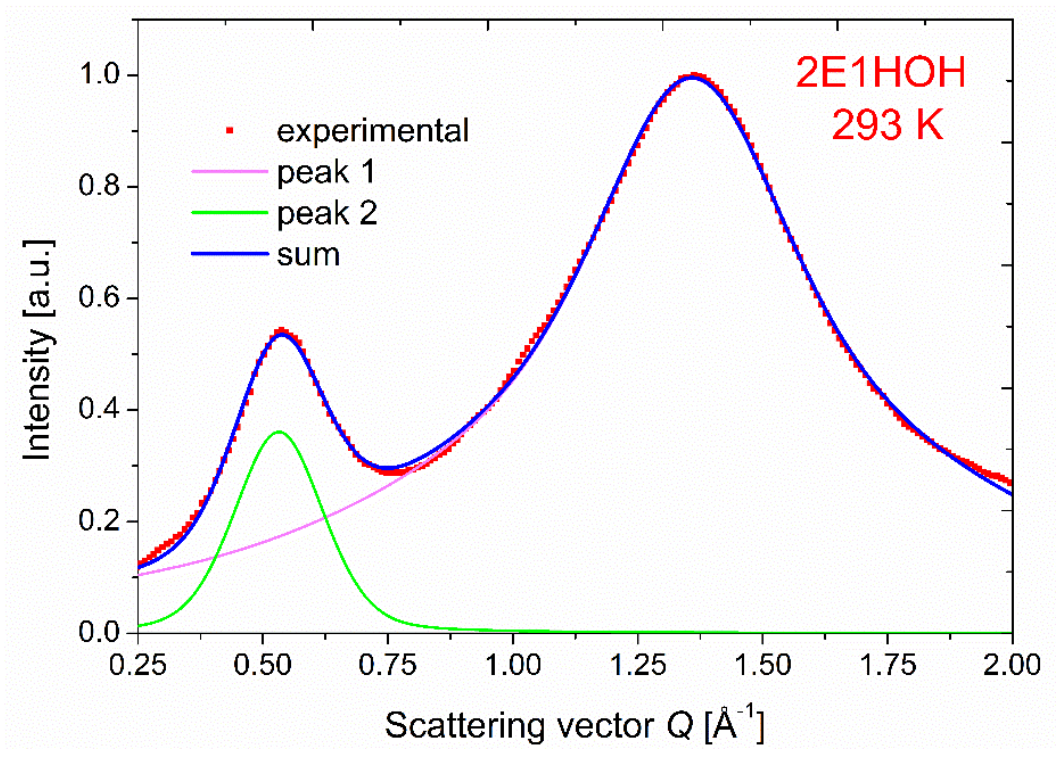

Figure S4. An example of a fit to the diffraction data with two PseudoVoigt functions for $2 \mathrm{E} 1 \mathrm{HOH}$ at $293 \mathrm{~K}$. 
Table S1. Structural parameters for the studied 2-ethyl-1-hexanol, 2-ethyl-1-hexylamine, 2-ethylhexanethiol, and 1-phenyl-2-butanol obtained from the analysis of the diffraction data measured at $293 \mathrm{~K}$ and $173 \mathrm{~K}$.

\begin{tabular}{|l|c|c|c|c|c|c|c|c|}
\hline $\begin{array}{l}\text { Structural parameters } \\
\text { obtained from } \\
\text { diffraction data fitting }\end{array}$ & \multicolumn{2}{|c|}{ 2E1HOH } & \multicolumn{2}{|c|}{ 2E1HNH } & \multicolumn{2}{c|}{ 2E1HSH } & \multicolumn{2}{c|}{ 1PH2BOH } \\
\cline { 2 - 9 } & $\mathbf{2 9 3}$ K & $\mathbf{1 7 3 ~ K}$ & $\mathbf{2 9 3}$ K & $\mathbf{1 7 3 ~ K}$ & $\mathbf{2 9 3}$ K & $\mathbf{1 7 3 ~ K}$ & $\mathbf{2 9 3}$ K & $\mathbf{1 7 3 ~ K}$ \\
\hline $\begin{array}{l}\text { main peak position } \\
Q_{\mathrm{mp}}\left[\AA^{-1}\right]\end{array}$ & 1.36 & 1.45 & 1.34 & 1.45 & 1.39 & 1.48 & 1.38 & 1.44 \\
\hline $\begin{array}{l}\text { pre-peak position } \\
Q_{\mathrm{pp}}\left[\AA^{-1}\right]\end{array}$ & 0.53 & 0.55 & 0.35 & 0.42 & - & 0.64 & 0.73 & 0.75 \\
\hline $\begin{array}{l}\text { repeating distance } \\
d_{\mathrm{mp}}[\AA]\end{array}$ & 4.62 & 4.32 & 4.70 & 4.34 & 4.52 & 4.25 & 4.55 & 4.35 \\
\hline $\begin{array}{l}\text { repeating distance } \\
d_{\mathrm{pp}}[\AA]\end{array}$ & 11.75 & 11.46 & 17.95 & 14.99 & - & 9.82 & 8.61 & 8.04 \\
\hline $\begin{array}{l}\text { main peak width } \\
F W H M_{\mathrm{mp}}\left[\AA^{-1}\right]\end{array}$ & 0.64 & 0.46 & 0.74 & 0.54 & 0.83 & 0.67 & 0.65 & 0.58 \\
\hline $\begin{array}{l}\text { pre-peak width } \\
F W H M_{\mathrm{pp}}\left[\AA^{-1}\right]\end{array}$ & 0.21 & 0.20 & 0.27 & 0.15 & - & 0.23 & 0.35 & 0.32 \\
\hline $\begin{array}{l}\text { coherence length } \\
L_{m p}[\AA]\end{array}$ & 9.75 & 13.20 & 8.44 & 11.54 & 7.57 & 9.38 & 9.67 & 10.83 \\
\hline $\begin{array}{l}\text { coherence length } \\
L_{\mathrm{pp}}[\AA]\end{array}$ & 29.92 & 31.15 & 23.27 & 41.88 & - & 27.30 & 17.95 & 19.64 \\
\hline $\begin{array}{l}\text { integrated intensity } \\
\text { of main peak } I_{\mathrm{mp}}\end{array}$ & 1.06 & 0.85 & 1.17 & 0.88 & 1.23 & 1.00 & 1.00 & 0.81 \\
\hline $\begin{array}{l}\text { integrated intensity } \\
\text { of pre-peak } I_{\mathrm{pp}}\end{array}$ & 0.11 & 0.07 & 0.07 & 0.09 & - & 0.01 & 0.05 & 0.04 \\
\hline
\end{tabular}

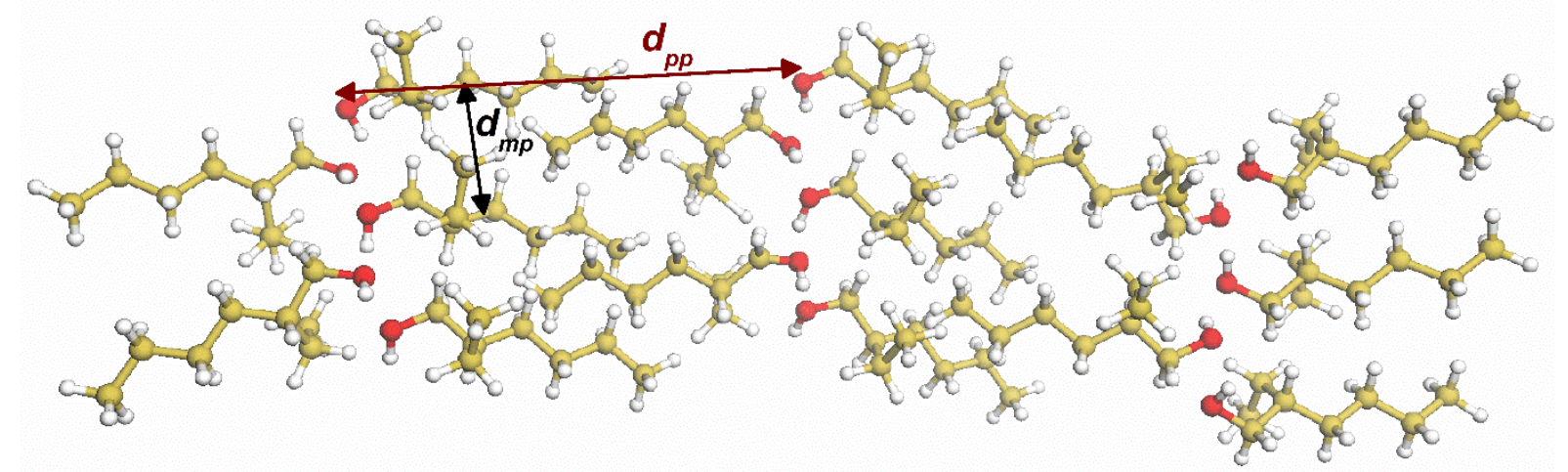

Figure S5. Sketch of the predicted supramolecular structure of $2 \mathrm{E} 1 \mathrm{HOH}$ at $293 \mathrm{~K}$. Typical repeating distances, $d_{m p}$ and $d_{p p}$, related with the appearance of the main diffraction peak and the pre-peak, respectively, are indicated by arrows. 


\section{Density Functional Theory calculations}

The calculated dipole moments and their components along the main molecular axes (x, y, $\mathrm{z}$ ) are given in Table S2. The geometry of the optimized lowest-energy conformation for $2 \mathrm{E} 1 \mathrm{HOH}, 2 \mathrm{E} 1 \mathrm{HNH}_{2}, 2 \mathrm{E} 1 \mathrm{HSH}$, and $1 \mathrm{PH} 2 \mathrm{BOH}$ is shown in Figure S6 a-d, respectively. It is worth to add that the calculated dipole moments for $2 \mathrm{E} 1 \mathrm{HOH}$ and $2 \mathrm{E} 1 \mathrm{HNH}_{2}$ are closed to the values determined experimentally $\left(1.76 \mathrm{D}\right.$ and $1.53 \mathrm{D}$, respectively $\left.{ }^{2,3}\right)$.

Table S2. Values of calculated total dipole moment and its components along three molecular directions $(\mathrm{x}, \mathrm{y}, \mathrm{z})$, showed in Figure S5, for 2E1HOH, 2E1HNH $2,2 \mathrm{E} 1 \mathrm{HSH}$, and 1PH2BOH.

\begin{tabular}{|l|c|c|c|c|}
\hline \multirow{2}{*}{ Compound } & \multicolumn{4}{|c|}{ Dipole moment [D] } \\
\cline { 2 - 5 } & $\mu_{x}$ & $\mu_{y}$ & $\mu_{z}$ & total $\mu$ \\
\hline 2E1HOH & 0.15 & -1.28 & 0.76 & 1.49 \\
\hline 2E1HNH 2 & -0.02 & -1.21 & 0.38 & 1.27 \\
\hline 2E1HSH & 1.50 & 0.34 & 1.04 & 1.85 \\
\hline 1PH2BOH & -0.73 & 0.36 & 1.44 & 1.66 \\
\hline
\end{tabular}
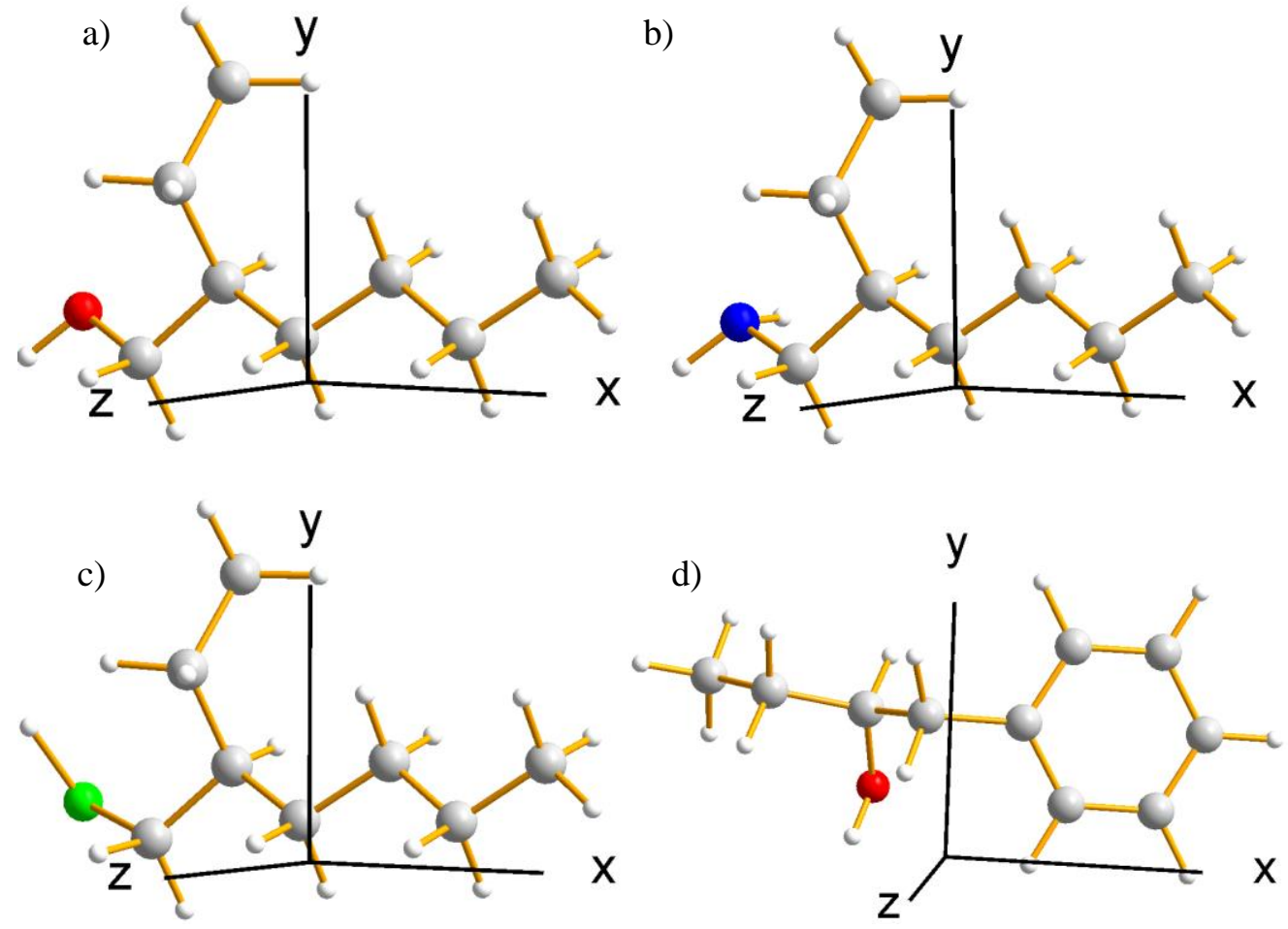

Figure S6. Optimized conformations of (a) $2 \mathrm{E} 1 \mathrm{HOH}$, (b) $2 \mathrm{E} 1 \mathrm{HNH}_{2}$, (c) $2 \mathrm{E} 1 \mathrm{HSH}$, and (d) $1 \mathrm{PH} 2 \mathrm{BOH}$ molecules and their orientation in xyz Cartesian coordination system used for calculation of dipole moment. 


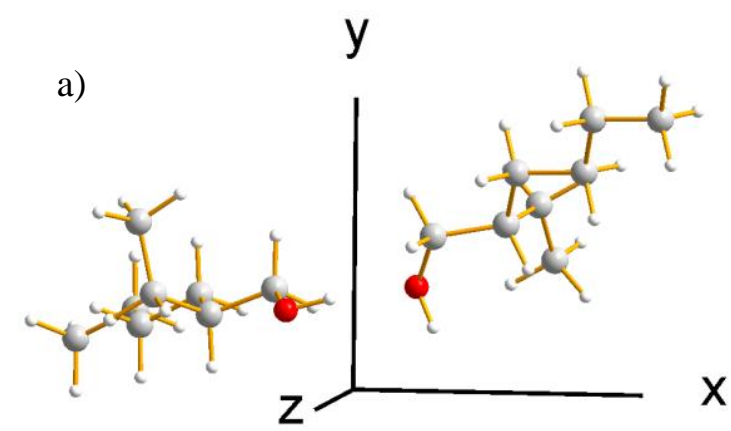

b)
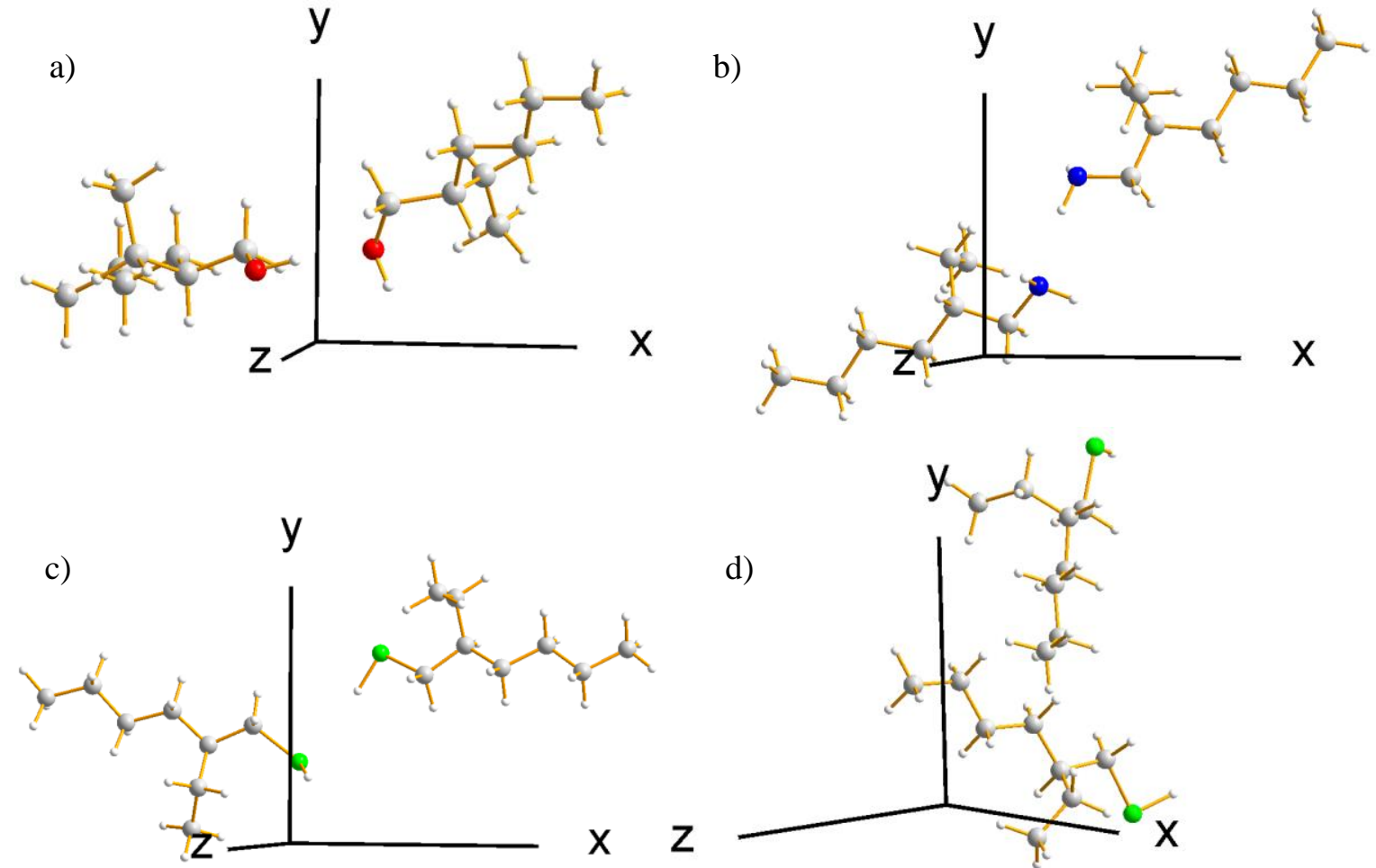

d)
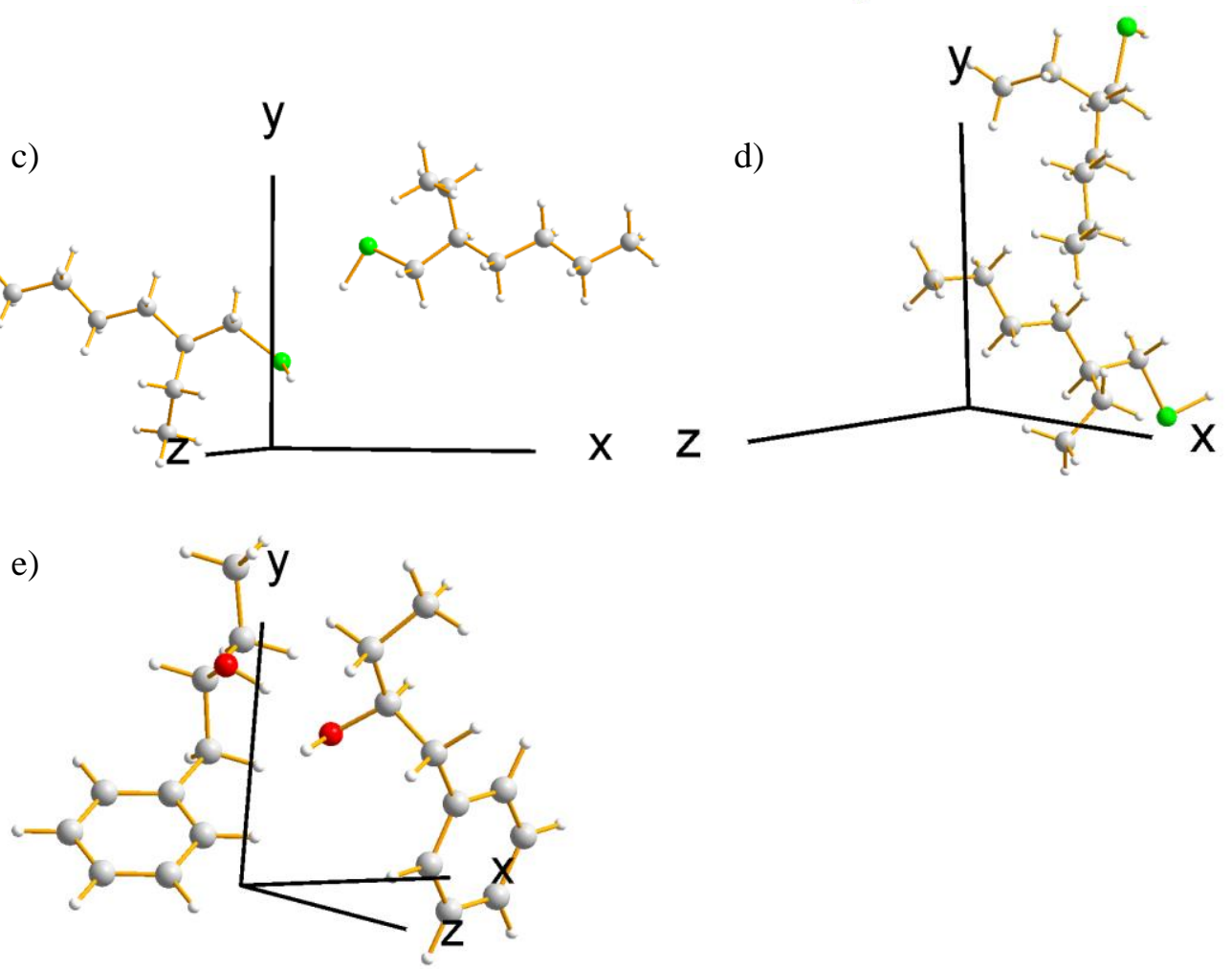

Figure S7. Optimized models of the most stable dimers for (a) $2 \mathrm{E} 1 \mathrm{HOH}$, (b) $2 \mathrm{E}^{\mathrm{HNH}} \mathrm{HN}_{2}$, (c) $2 \mathrm{E} 1 \mathrm{HSH}$, (d) 2E1HSH - perpendicular system after optimization of starting model with van der Waals interacting molecules aligned parallel, and (e) $1 \mathrm{PH} 2 \mathrm{BOH}$. For $2 \mathrm{E} 1 \mathrm{HOH}, 2 \mathrm{E} 1 \mathrm{HNH}_{2}$ and $1 \mathrm{PH} 2 \mathrm{BOH}$ dimers interacting via $\mathrm{H}$ bonds are energetically preferred and the most stable, for 2E1HSH dimers interacting via $\mathrm{H}$ bonds or van der Waals interactions the energy of the system is comparable.

Table S3. Energy of the optimized monomers showed in Figure S6 and dimers showed in Figure S7 for $2 \mathrm{E} 1 \mathrm{HOH}, 2 \mathrm{E} 1 \mathrm{HNH}_{2}, 2 \mathrm{E} 1 \mathrm{HSH}$, and $1 \mathrm{PH} 2 \mathrm{BOH}$.

\begin{tabular}{|l|c|c|c|}
\hline \multirow{2}{*}{ Compound } & \multicolumn{3}{|c|}{ Energy $[\mathrm{kcal} / \mathrm{mol}]$ (uncertainty $\pm 1 \mathrm{kcal} / \mathrm{mol}$ ) } \\
\cline { 2 - 4 } & $E_{\text {monomer }} \cdot 10^{5}$ & $E_{\text {dimer }} \cdot 10^{5}$ & $E_{\text {dimer }}-2 \cdot E_{\text {monomer }}$ \\
\hline 2E1HOH & -2.453291 & -4.906666 & -7.38 \\
\hline 2E1HNH & -2.328633 & -4.657304 & -3.92 \\
\hline 2E1HSH & -4.479951 & -8.959929 & -2.65 \\
\cline { 2 - 4 } 2E1HSH perpendicular & & -8.959903 & 0.13 \\
\hline 1PH2BOH & -2.916414 & -5.832880 & -5.26 \\
\hline
\end{tabular}




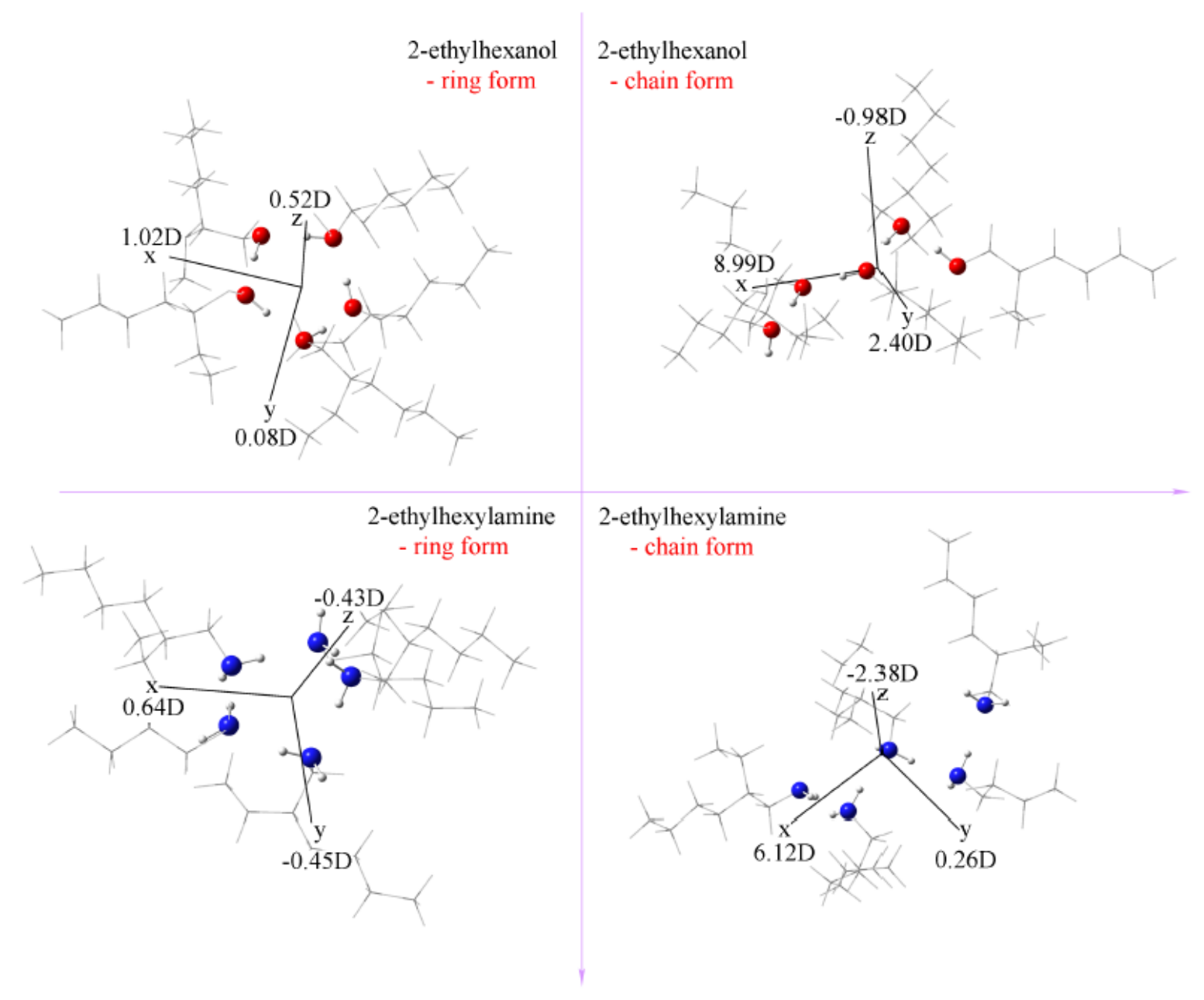

Figure S8. Visualization of the chain- and ring-like structures for $2 \mathrm{E} 1 \mathrm{HOH}$ and $2 \mathrm{E} 1 \mathrm{HNH}_{2}$ together with the respective $\mathrm{x}, \mathrm{y}$ and $\mathrm{z}$ - components of their effective dipole moments. The chain-like structures are energetically more preferred than the circular associates for $2 \mathrm{E} 1 \mathrm{HOH}$ and and less preferred for $2 \mathrm{E} 1 \mathrm{HNH}_{2}$. The pictures are based on DFT calculations performed in reference ${ }^{4}$.

(1) Büning, T.; Lueg, J.; Bolle, J.; Sternemann, C.; Gainaru, C.; Tolan, M.; Böhmer, R. Connecting structurally and dynamically detected signatures of supramolecular Debye liquids. J. Chem. Phys. 2017, 147, 234501.

(2) Yaws, C. L. Thermophysical properties of chemicals and hydrocarbons; William Andrew: 2008.

(3) Budenstein, P. B. Digest of Literature on Dielectrics; National Academy of Science: 1973.

(4) Adrjanowicz, K.; Jakobsen, B.; Hecksher, T.; Kaminski, K.; Dulski, M.; Paluch, M.; Niss, K. Communication: Slow supramolecular mode in amine and thiol derivatives of 2-ethyl-1-hexanol revealed by combined dielectric and shear-mechanical studies. J. Chem. Phys. 2015, 143, 181102. 